\title{
An Evaluation of Pradhan Mantri Jan Dhan Yojana (PMJDY): A Case Study of Aligarh District
}

\author{
Md. Tarique ${ }^{1 *}$, Nisar Ahmad Khan ${ }^{2}$, Dr. Maria Khan ${ }^{3}$, Mr. Md Abusaad ${ }^{4}$, Dr. Musab Mubarak Ilmi Qadri ${ }^{5}$ \\ ${ }^{1}$ Professor \& Director ICSSR-IMPRESS project, Department of Economics, Aligarh Muslim University, Aligarh, Uttar Pradesh 202001, India \\ ${ }^{2}$ Professor \& Co-Director ICSSR-IMPRESS project and Dean Faculty of Social Sciences, Aligarh Muslim University, Aligarh, Uttar Pradesh 202001, \\ India \\ ${ }^{3}$ Assistant professor (C) \& Co-Director ICSSR-IMPRESS project, Department of Economics, Aligarh Muslim University, Aligarh, Uttar Pradesh \\ 202001, India \\ ${ }^{4}$ Research Assistant, Department of Economics, Aligarh Muslim University, Aligarh, Uttar Pradesh 202001, India \\ ${ }^{5}$ Field Investigator, Department of Economics, Aligarh Muslim University, Aligarh, Uttar Pradesh 202001, India
}

DOI: $10.36348 /$ sjef.2020.v04i12.002

| Received: 19.11 .2020 | Accepted: 02.12.2020 | Published: 05.12.2020

*Corresponding author: Md. Tarique

\section{Abstract}

Indian planners since independence have tried to put financial inclusion at the centre of their policy. But despite nationalization of banks, establishment of cooperative societies, and many other such policies have not been able to substantially improve the livelihood of the poor. In view of pathetic financial coverage over a period of time, PMJDY was launched in 2014 as a comprehensive plan based on six pillars viz. Universal Access to Banking Facilities, Providing Basic Banking Accounts, Financial Literacy, Credit Guarantee Fund, Micro Insurance and Pension Scheme. The present study is an attempt to look into the financial literacy, financial penetration, and poverty status of PMJDY account holders in Aligarh district. The study also investigates gender wise and caste wise differential among PMJDY account holders. The study is based on primary data for which a sample of 100 households was taken on a random basis. The sample was collected from three villages of Lodha and Atrauli blocks of Aligarh district. The results show a significant gender and caste wise differential with regard to transaction by self, awareness about DBT, savings, and receiving \& activating Rupay debit card. Further, there exists caste wise but not gender wise differential because of motivation/reason behind opening an account in PMJDY and agreement on fulfillment of government's objectives. More than 80 percent of the respondents strongly agree/agree with the notion that they opened PMJDY account in anticipation that Rs.15 lakhs will be transferred into their account as promised by the present government. This simply shows the degree of political innocence of poor rural masses. Gender wise analysis clarifies that there exist a significant difference between male and female households in terms of multi dimensionally poor population but not on account of average intensity of deprivation. Dimension wise significant differential is present on education and living standard dimension but not on health dimension. Taking general category as base category, the MPI is 70 percent higher for OBCs and 230 percent larger for SCs. This shows caste wise large disparity on poverty front among PMJDY beneficiaries.

Keywords: Aligarh, PMJDY, Banking services, Financial Literacy, Financial Penetration, Multi dimensional Poverty.

Copyright (C) 2020 The Author(s): This is an open-access article distributed under the terms of the Creative Commons Attribution 4.0 International License (CC BY-NC 4.0) which permits unrestricted use, distribution, and reproduction in any medium for non-commercial use provided the original author and source are credited.

\section{ACKNOWLEDGEMENT}

We are thankful to ICSSR-IMPRESS for providing financial help in conducting the survey. This research paper is part of the project sanctioned by ICSSR-IMPRESS, New Delhi.

\section{INTRODUCTION}

Financial inclusion has been at the core of Indian planners since independence. Many initiatives were taken in this direction such as nationalization of banks, establishing Regional Rural Banks, Cooperative Banks, appointing Banking Correspondence Agents
(BCA), launching of Swabhiman and Swavlambhan Schemes, introducing micro finance, opening up of nofrills account, provision of keeping 25 percent of bank branches in rural areas, initiating the model of Bharatiya Mahila Bank, simplifying the KYC norms and so on. As the objectives of financial inclusion was not fulfilled to the desired extent, the government launched Pradhan Mantri Jan Dhan Yojana (PMJDY) with an innovative idea. The PMJDY, roughly translated as 'People's Wealth Scheme' was announced by the Prime Minister in his Independence Day speech with the slogan 'Mera Khata -Bhagya Vidhata' which 
means 'My Bank Account - The Creator of the Good Fortune' [1].

The purpose of financial inclusion is to help people to meet their basic needs such as healthy food, clean water, housing, education and healthcare. This also assists the businesses that provide these services, and empowers the customers to have more consistent and reasonable access to them. An inclusive financial system is indispensable organisation in every country. While financial inclusion alone could not alleviate poverty, it can help people build better lives. It can help individuals to start businesses, and help small businesses grow into larger ones. Financial services can also aid small farmers to become a part of the formal economic system for two-way flow of information and income. The economy can flourish more rapidly and in manners more favourable to poor people. The policy makers have been concentrating on financial inclusion of Indian rural and semi-rural areas mainly for three most important pressing needs namely creating a platform for inculcating the habit to save money, providing formal credit avenues and plug gaps and leaks in public subsidies and welfare programmes.

Census 2011 [2] estimated that out of 24.67 crore households in the country, 14.48 crore $(58.7 \%)$ households had access to banking services. Out of 16.78 crore rural households, 9.14 crore $(54.46 \%)$ were availing banking services. Of the 7.89 crore urban households, 5.34 crore $(67.68 \%)$ households were availing banking services.

The CRISIL Inclusive Scores for measuring financial inclusion at all India level was 53.2 in 2014, the year PMJDY was launched [3]. The same index value for Aligarh district was only 42.6. This shows that the district is very undersized with regard to financial inclusion. In terms of rank, it was 365 out of 656 districts ranked.

Considering small financial coverage and its narrow applicability, PMJDY was launched in 2014 which is a comprehensive financial inclusion programme, targeting opening up of 7.5 crore new accounts within five months with insurance and pension facilities. However, it was over achieved and 12.5 crore accounts were opened under the scheme. It aims at providing Bank Account to every household in the country and make available the basic banking services facilities. Under the provisions of the scheme, the account holder is entitled to get accidental insurance worth Rs. 1 lakh (now increased to Rs. 2 lakh), overdraft of up to Rs. 5,000 (now increased to Rs. 10,000) and life insurance of Rs. 30,000. PMJDY is based on six pillars viz. Universal Access to Banking Facilities, Providing Basic Banking Accounts, Financial Literacy, Credit Guarantee Fund, Micro Insurance and Pension scheme.
The present study is based on the primary data collected from Aligarh district of UP. The study tries to look into whether there exists gender wise and caste wise differential with regard to financial literacy and financial penetration among PMJDY account holders. The study also stares at gender wise and caste wise differential on poverty condition among PMJDY account holders.

The rest of the article is organized as follows. Section 2 reviews related existing literature. Objectives and hypotheses are structured in Section 3. In Section 4, the database and methodology is explained. Section 5 is given to data analysis. Section 6 presents conclusion.

\section{LITERATURE REVIEW}

Many studies have been done on financial inclusion and its impact on poverty. These studies are either country specific or region specific. However, very few studies have been done on PMJDY in general and poverty conditions of PMJDY account holders in particular.

Studies on PMJDY have been done by Swain and Jain [4], Saini and Guleria [5], Singh and Naik [6], Guleria and Verma [7], Nimbrayan, Tanwar, and Tripathi [8], Guntupalli [9], Patnaik et al., [10], Paramasivan [11], Aswathy and Shiny [12], Das [13] and Paramasivan and Kamaraj [14].

Swain and Jain [4] assess the impact of PMJDY on poor in Odisha with a sample of 200 respondents (50 each from 4 districts). Study reveals that financial awareness among the people has improved and encouraged saving habits among them. Further, this scheme reduces poverty and prevents ignorant sections of the society from the clutches of money lenders. Saini and Guleria [5] use multistage sampling to assess the awareness among masses in Chamba district of Himachal Pradesh. They have noted that banks are doing a fantastic job of including the excluded segment, and people also appreciate their efforts, but still a lot is to be done. Singh and Naik [6] study is based on primary data, for which data was randomly collected from six panchayats of Gubbi Taluk in Karnataka. They find that the PMJDY programme has been widely effective in rural areas as a strategy for financial inclusion, especially for women. Similarly, individuals who do not have formal education have mostly opened PMJDY accounts. Guleria and Verma [7] in their research, explore the perception of rural population of Chamba and Shimla districts with regard to PMJDY. They conclude that financial benefits encourage saving habits, social development and eliminate corruption. In their study, Nimbrayan, Tanwar, and Tripathi [8] find that PMJDY scheme plays an important role in establishing a universal financial services platform for Indian citizens. Guntupalli [9] uses both primary and secondary data to know the impact of PMJDY on urban population in 
Mumbai. He identifies that people's low income imparts a disincentive to open the accounts and continue the transactions through banks. Patnaik et al., [10] in their study observe that poor people are not interested in opening bank accounts as their zero savings. Paramasivan [11] observed that public sector banks implementing the national mission "PMJDY" are working well. Aswathy and Shiny [12] found that many people have opened bank accounts due to PMJDY wider coverage. In his study, Das [13] shows that through PMJDY, financial transactions have improved for the poorer section. Paramasivan and Kamaraj [14] emphasize the role of public sector banks in contributing PMJDY. They reveal that the PMJDY scheme had created an impressive result in the banking sector about eradicating financial untouchability in the country.

The present work is distinct from the works cited above as it takes into account the financial literacy, financial penetration and multidimensional poverty issues simultaneously among PMJDY account holders. Using one way ANOVA the study attempts to look into whether there exist any gender wise and caste wise differential among PMJDY account holders with regard to above variables. None of the above cited studies have looked into the issue from these angles.

\section{OBJECTIVES AND HYPOTHESES}

This study is carried out with the following objectives:

1. To find out extent of gender wise financial literacy and penetration among PMJDY account holders.

2. To uncover the level of caste wise financial literacy and penetration among PMJDY account holders.

3. To understand caste and gender wise multidimensional poverty differential among PMJDY account holders.

The study tries to test the following Hypotheses:

1. There is no significant difference with respect to financial literacy and penetration among PMJDY account holders between male and female.

2. There is no caste wise significant difference in financial literacy and penetration among PMJDY account holders.

3. There is no significant caste and gender wise differential on account of multi dimensional poverty among PMJDY account holders.

\section{DATABASE AND METHODOLOGY}

The study is based on primary data for which a sample of 100 households were taken using multi- stage stratified random sampling. Blocks were stratified on the basis of SCs population, generally considered as socially deprived section. Lodha block has highest number of SCs Population while the number of SCs Population in Atrauli is low (i.e. $3^{\text {rd }}$ from bottom). These two blocks were selected for the study. The sample is collected from three villages of these blocks of Aligarh district. As the purpose of the study is to find financial literacy, financial penetration and poverty status among PMJDY account holders, the respondents are asked questions on related issues. The poverty has used the concept of multi-dimensional poverty, which includes education, health, and income related issues.

Questions related to reasons/motivation behind opening bank account under PMJDY are asked on five point Likert scale, ranging from strong disagreement to strong agreement. One way ANOVA is applied to have an idea whether gender wise and caste wise differential exist in perception. The questions examine whether respondents open account to avail zero balance account facility, gain direct benefit transfer (DBT), use overdraft facility, get insurance benefits etc.

The statistical software SPSS and MS-Excel is used for descriptive statistics and applying one way ANOVA. Multi-dimensional Poverty Index (MPI) is calculated by applying Alkire and Foster (2007) approach at aggregate and household level using three dimensions and eleven indicators. Decomposition analysis is employed to identify dimension wise deprivations. We have taken the poverty cut-off ' $k$ ' at 3.3 indicating that those deprived in at least 33 percent of the weighted indicators are considered as multidimensional poor.

MPI is calculated by using the formula:

\section{$\mathbf{M P I}=\mathbf{H} * \mathbf{A}$}

Where,

MPI = Multidimensional Poverty Index

$\mathrm{H}=$ Incidence of poverty or headcount ratio i.e. the percentage of people who are multidimensional poor.

$\mathrm{A}=$ Average intensity of deprivations i.e. the average proportion of indicators in which the multidimensional poor are deprived.

\section{$\mathbf{H}=\mathbf{q} / \mathbf{n}$}

Where,

' $\mathrm{q}$ ' is the number of people who are multidimensional poor at $\mathrm{k}=3.3$

' $n$ ' is the total population of the sample.

\section{$A=\mathbf{d k} / q$}

Where,

' $\mathrm{dk}$ ' is the sum (total) of the deprivation score of multidimensional poor.

The MPI at household level is calculated as:

$$
\mathrm{MPI}_{\mathrm{h}}=\mathrm{H}_{\mathrm{h}} * \mathbf{A}_{\mathrm{h}}
$$

$\mathrm{MPI}_{\mathrm{h}}$ is the Multidimensional Poverty Index for the respondent household

$\mathrm{H}_{\mathrm{h}}$

$\mathrm{W}_{1} \mathrm{IN}_{1}+\mathrm{w}_{2} \mathrm{IN}_{2}+\mathrm{w}_{3} \mathrm{IN}_{3}+\mathrm{w}_{4} \mathrm{IN}_{4}+\mathrm{W}_{5} \mathrm{IN}_{5}+\mathrm{W}_{6} \mathrm{IN}_{6}+\mathrm{w}_{7} \mathrm{IN}_{7}+\mathrm{W}_{8} \mathrm{I}$

$\mathrm{N}_{8}+\mathrm{w}_{9} \mathrm{IN}_{9}+\mathrm{w}_{10} \mathrm{IN}_{10}+\mathrm{w}_{11} \mathrm{IN}_{11}$

$\mathrm{H}_{\mathrm{h}}$ is the incidence of poverty (multidimensional poor household). It is used to identify whether the respondent household is multidimensional poor or not. 
$\mathrm{W}_{\mathrm{i}} \mathrm{IN}_{\mathrm{i}}$ is the weighted score to indicator $\mathrm{i}$ where $\mathrm{i}=$ $1,2,3, \ldots .11$.

' $A_{h}$ ' is the average intensity of deprivations (A) of the respondent household being calculated as:

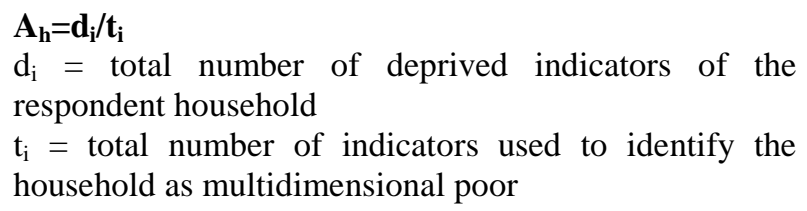

The MPI decomposed by dimensions at household level is calculated as:
Contribution of dimension ' $\mathrm{i}$ ' to $\mathbf{M P \mathbf { I } _ { \mathbf { i } }}=$ $\mathrm{w}_{\mathrm{i}} \mathrm{D}_{\mathbf{i}} / \mathbf{M P I}_{\mathbf{h}} * \mathbf{1 0 0}$

' $\mathrm{W}_{\mathrm{i}} \mathrm{D}_{\mathrm{i}}$ ' is the total weighted score of dimension ' $\mathrm{i}$ ' (combined weighted score of indicators of dimension 'i')

$\mathrm{MPI}_{\mathrm{h}}$ is the total deprived weighted score of all dimensions.

\section{DATA ANALYSIS \\ General Information}

This study is based on primary data collected from 100 households, all having PMJDY accounts. Out of these, 18 respondents already had saving bank account. The details of the respondents are given below:

\begin{tabular}{|l|l|}
\hline Classification & Numbers \\
\hline Sex wise & Male $-57 \%$, Female $-43 \%$ \\
\hline Caste wise & SC $-7 \%$, OBC $-69 \%$, General - 24\% \\
\hline Literacy & Illiterate - 65\%, Literate - 35\% \\
\hline Family Monthly Income & $\begin{array}{l}\text { Less than Rs. 1000 - 6\%, Rs. 1000-3000 - 11\% } \\
\text { Rs. 3001-5000 - 31\%, More than Rs. 5000 - 52\% }\end{array}$ \\
\hline
\end{tabular}

The study reveals that literacy has an impact on the saving habits of the households. Out of the 65 illiterate households, $59(90.77 \%)$ do not save any amount and the remaining $6(9.23 \%)$ save less than Rs. 500 per month. Among the 35 literates, 11 households $(31.43 \%)$ have the saving habits.

\section{Credit Penetration, Deposit Penetration and Insurance Penetration}

Initially overdraft facility upto Rs. 5000 were available under PMJDY to the eligible account holders, which further increase to Rs. 10000. In our survey, we found that only $4 \%$ households have availed the overdraft facility.

Data reveals that 83 percent households do not save any amount and only 17 percent save from their various sources of income. Further, 37 percent households prefer to keep money with the banks and 63 percent households prefer cash with themselves.

As far as deposit or withdrawal facility is concerned, data show that 52 percent have availed deposit and withdrawal facilities from the banks under PMJDY account. 68 percent of the literate households have availed deposit/withdrawal facility for not more than three times.

PMJDY provides accident insurance cover of Rs. 2 lakh and life insurance cover of Rs. 30000 to the eligible account holders. But in our survey, none of the households have availed these facilities.

PMJDY scheme provides the facility of Atal Pension Yojana, Pradhan Mantri Jeevan Jyoti Bima Yojana and Pradhan Mantri Suraksha Bima Yojana to the eligible account holder. But none of the households in our survey are aware about the pension scheme and hence could not get the benefit.

To access the banking facility, the location of the bank plays a very important role. Data reveals that 39 percent households have accounts in the banks within $2 \mathrm{~km}$ of distance and 61 percent have opened their accounts in the banks within the range of $2-5 \mathrm{~km}$. Thus, 100 percent coverage lies within PMJDY targeted distance.

\section{Gender wise Analysis}

Gender wise data reveals that 55.81 percent female households are not able to do banking transaction by themselves, while 31.57 percent male households are unable to do their regular transaction by themselves. Only two out of forty three female households (i.e. $4.65 \%$ ) are aware about DBT, while in case of male, 22.81 percent have awareness about DBT.

None of the female households have saving from their income. Among male households, 29.82 percent save an amount less than Rs.1000 and only 3.51 percent save more than Rs. 1000. Female households prefer to keep their money with themselves and only 4.65 percent prefer to have money with the bank. While in case of male households, 57.89 percent use the banking facilities to deposit saving amount.

It is observed that 90.70 percent female households and 80.70 percent male households have deposited some amount (mostly Rs100 or Rs 500) for opening account under PMJDY. Data also show that only 30.23 percent female households have received Rupay debit card, and all of them have activated and used it for transaction purpose. While 61.40 percent male households have received debit card, of which only 51.43 percent activated their card and transacted 
from them. 69.77 percent female households did not avail the facility of deposit or withdrawal. On the other hand, 68.42 percent male households are availing the facility of deposit/withdrawal. As far as borrowing is concerned, 69.77 percent females and 68.42 percent male households are still borrowing from moneylenders. None of the account holders got the benefits of borrowing facility under the scheme.

Questions related to reasons/motivation behind opening bank account under PMJDY was asked on five point likert scale, ranging from strong disagreement to strong agreement. The gender wise classification shows that 51.16 percent female households strongly agree/agree that they will be benefitted by the objectives of PMJDY whereas only 38.60 percent male households strongly agree/agree with these objectives. Component wise analysis reflects higher leaning towards DBT facility ( $83.72 \%$ ), followed by overdraft facility $(51.16 \%)$ and free accidental insurance facility (55.81\%) under PMJDY behind the reasons for opening account by female population. For male, DBT (80.70\%) is found to be the major motivational force, followed by overdraft facility (35.09\%) and Rupay debit card (35.09\%). 83.72 percent of female households and 80.70 percent of male households strongly agree/agree that they have opened an account under PMJDY to access different government benefits and subsidies. On the other hand, 30.23 percent of the female households and only 10.52 percent of the male households strongly agree/agree that the reason behind opening an account under PMJDY is to deposit savings in the future.

The above analysis is in line with our first objective and first hypothesis. So long as transaction by self, awareness about DBT, savings and receiving \& activating Rupay debit card is concerned, there exists a significant difference between male and female household. In case of borrowing both male and female households have high dependency for moneylenders. The reasons/motivation behind opening bank account under PMJDY also confirms significant gender differentials.

\section{Caste wise Analysis}

To know the status among social groups, caste wise analysis is done. Results show that 65.22 percent households from OBC category and 54.17 percent households from general category are able to do their banking transactions. But none of the households from SC category could do their banking transaction by themselves. It is found that 10.14 percent households from OBC category and 29.17 percent belonging to general category have awareness about DBT but none of the households from SC category are aware about DBT.

As far as saving habits are concerned, 15.94 percent OBCs save less than Rs. 500 and SCs do not save any amount from their earning. 62.32 percent from
OBC category prefer to keep their money with the banks. There are 25 percent households from general category who save some amount, upto less than Rs 1500. 54.17 percent households from general category prefer to use the banking facilities to deposit their saving amount.

Statistics shows that 94.20 percent households from OBC category, 54.17 percent households from general category and all the households from SC category have paid some amount at the time of opening account under PMJDY.

It is observed that 50.72 percent households from OBC category have received Rupay debit, of which 43.86 percent households have activated and transacted from it. Among general category, 54.17 percent households have received the debit card and all of them have activated their card and transacted from it. In the case of SC, none of the households have received Rupay debit card. Further, 53.62 percent OBC households have availed the facility of deposit/withdrawal. Among general category, 54.17 percent are availing this facility and in case of SC households, only 28.57 percent are availing the deposit/withdrawal facility.

As far as borrowing is concerned, all the households from SC category depend on moneylenders. 71.01 percent households form OBC category and 54.17 percent from general category are dependent on moneylenders.

The results obtained from motivation/reason behind opening PMJDY account indicate that 28.57 percent of the SC households strongly agree/agree that the government's objectives will benefit them. They show a strong agreement for using overdraft facility, taking subsidies and other benefits and getting accidental insurance benefit (each 71.43 percent). 43.48 percent of the households from the OBC category and 50 percent from the general category strongly agree/agree with these objectives. 71.43 percent households from the SC category, 81.16 percent from $\mathrm{OBC}$ and 83.33 percent from general category strongly agree/agree that they opened an account under PMJDY to access the different government benefits and subsidies. 18.84 percent of OBC households, 25 percent from the general category and none of the households from SC category strongly agree/agree that they opened an account under PMJDY to deposit savings in the future.

To sum up, 43 percent households strongly agree/agree that they will be benefitted from the government's objectives behind PMJDY. 82 percent households strongly agree/agree that they opened an account under PMJDY to access the different government benefits and subsidies and 19 percent strongly agree/agree that the reason behind opening an 
account under PMJDY is to deposit savings in the future.

The above analysis is in line with our second objective and second hypothesis. With regard to transaction by self, awareness about DBT, savings, receiving \& activating Rupay debit card and borrowings from money lenders are concerned, there exists caste wise significant differential among households. Further, there exists caste wise differential with regard to the motivation/reason behind opening an account in PMJDY and agreement on fulfillment of government's objectives.

One probe we tried to examine was related to opening PMJDY account in anticipation that Rs.15 lakhs will be transferred into the account as promised by the present government. More than 80 percent respondent from each strata strongly agree/agree with this notion. This simply shows the degree of political innocence of poor rural masses.

\section{Analysis of Multidimensional Poverty among PMJDY account holders: \\ Within the sample 39 percent of the households are multi-dimensionally poor (they are deprived in at least 33 percent of the weighted indicators). The MPI poor households suffer from deprivation in 43.54 percent of the indicators on an average. The overall MPI score for the district is 0.17 .}

Table-1: Multidimensional Poverty Index (MPI)

\begin{tabular}{|l|l|l|}
\hline Multidimensional Poverty Index (MPI) & Incidence of Poverty (H) & Average intensity of deprivations (A) \\
\hline 0.17 & $39.00 \%$ & $43.54 \%$ \\
\hline
\end{tabular}

Source: Author's calculation based on primary survey data

Out of 39 multi-dimensionally poor households, the MPI score varies from 0.10 to 0.36 . The dimensional deprivation reveals that on an average 36.24 percent are deprived in education (Range: Zero to 87.5) and 33.20 percent in health dimension (Range: Zero to 46.67) while living standard deprivation level is 30.56 percent (Range: 12.50 to 58.82 ).

\section{Gender wise Multidimensional Poverty}

The gender-wise result reveals that the MPI score of male households is 0.15 . Out of these 35.09 percent of the households are multi-dimensionally poor. The average intensity of deprivation is 43.51 percent.
Deprivation at the dimensional level lets us know that 42.76 percent households are deprived in education dimension, 31.09 percent in health and 26.15 percent in living standards.

The MPI score of female households is 0.19. 44.19 percent of the households are multidimensionally poor. The average intensity of deprivation is 43.57 percent. The percent contribution of deprivation at a dimensional level is 29.07 for education, while 35.53 percent for health and 35.40 percent for the living standard.

Table-2: Multidimensional Poverty Index (MPI) of Gender

\begin{tabular}{|l|l|l|l|}
\hline Gender & Multidimensional Poverty Index (MPI) & Incidence of Poverty (H) & Average intensity of deprivations (A) \\
\hline Male & 0.15 & $35.09 \%$ & $43.51 \%$ \\
\hline Female & 0.19 & $44.19 \%$ & $43.57 \%$ \\
\hline
\end{tabular}

Source: Author's calculation based on primary survey data

Gender wise analysis clarifies that there exist a significant difference between male and female households in terms of multi dimensionally poor population but not on account of average intensity of deprivation. Dimension wise significant differential is present on education and living standard dimension but not on health dimension. This observation is in line with our third objective and corresponding hypothesis.

\section{Caste wise Multidimensional Poverty}

A caste wise study reveals that among SCs 71.43 percent of the households are multidimensionally poor with average intensity of deprivation at 44.45 percent. The overall MPI score of the SC households in the district is recorded at 0.33 . The average dimension wise deprivation for education, health and living standard is 49.27, 25.93 and 24.80 respectively.
The MPI score of OBC is observed as 0.17 . Out of 69 OBC households, 37.68 percent are multidimensionally poor. The average intensity of deprivation is 43.88 percent. Contribution of deprivation at dimensional level makes us known that 26.03 percent of households are deprived in education while 38.97 percent in health dimension and 35 percent in living standards.

The MPI score of the general category of households is 0.10 . The incidence of poverty is 29.17 percent. The average intensity of deprivation is recorded at 33.34 percent. Dimensional level study tells that, on an average, 53.80 percent of households are deprived in education dimension and 24.63 percent in health while 21.56 percent in the living standard. 
Table-3: Multidimensional Poverty Index (MPI) of Castes

\begin{tabular}{|l|l|l|l|}
\hline Caste & $\begin{array}{l}\text { Multidimensional } \\
\text { Poverty Index (MPI) }\end{array}$ & $\begin{array}{l}\text { Incidence of } \\
\text { Poverty (H) }\end{array}$ & $\begin{array}{l}\text { Average intensity of } \\
\text { deprivations (A) }\end{array}$ \\
\hline SCs & 0.33 & $71.43 \%$ & $44.45 \%$ \\
\hline OBCs & 0.17 & $37.68 \%$ & $43.88 \%$ \\
\hline Gen & 0.10 & $29.17 \%$ & $33.34 \%$ \\
\hline
\end{tabular}

Source: Author's calculation based on primary survey data

Taking general category as base category, the MPI is 70 percent higher for OBCs and 230 percent larger for SCs. The incidence of poverty is also very high for SCs, 142 percent higher than the general category while it is 29 percent for OBCs. This shows caste wise large disparity on poverty front among PMJDY beneficiaries. This rejects our hypothesis that there exists no caste wise disparity among PMJDY beneficiaries on poverty façade.

\section{CONCLUSION}

The present study has looked into the financial literacy, financial penetration and multi dimensional poverty concerns of the PMJDY account holders in Aligarh district five years after its commencement. The study has also tried to find whether gender and caste wise differential exists among account holders on the above mentioned aspects. The results obtained pronounce that there exist gender wise and caste wise differentials so long as transaction by self, awareness about DBT, savings and receiving \& activating Rupay debit card are concerned. So policies need to be designed to target women and SCs for improving financial literacy and progressing financial penetration among them. On the poverty front, 39 households are multi-dimensionally poor and the MPI score varies from 0.10 to 0.36 . Gender wise analysis clarifies that there exist a significant difference between male and female households in terms of multi dimensionally poor population but not on account of average intensity of deprivation. The MPI is 70 percent higher for OBCs and 230 percent larger for SCs. The incidence of poverty is also very high for SCs, 142 percent higher than the general category. This shows caste wise large disparity on poverty front among PMJDY beneficiaries. The study also confirms high dependency on money lenders for the financial requirement. The condition is more severe among OBCs and SCs. So, the scheme should focus more on SCs and OBCs population. This will not only bring this section out of the clutches of poverty but would also lead to a reduction in inequality within that group.

\section{REFERENCES}

1. Mohan, B. (2014). Pradhan Mantri Jan Dhan Yojana: Features, needs and challenges, International Journal of Marketing Financial Services and Management Res, 13:111-17.
2. Census. (2011). Office of the Registrar General \& Census Commissioner, Ministry of Home Affairs, Government of India.

3. CRISIL - An index to measure India's progress on financial inclusion, based on data provided by the Reserve Bank of India and Micro Finance Institutions Network.

4. Swain, N., \& Jain, A. (2019). Impact of public intervention on poor in Odisha: Special focus on Pradhan Mantri Jan-Dhan Yojana, International Journal of Innovative Technology and Exploring Engineering (IJITEE), 8(11S2).

5. Saini, V., \& Guleria, Y. (2018). Assessing inclusive growth through financial inclusion model of PMJDY, International Journal of Research in Humanities, Arts and Literature, 6(2), 263-270.

6. Singh, C., \& Naik, G. (2018). Financial inclusion after PMJDY: A case study of Gubbi Taluk, Tumkur, Working Paper, No: 568, IIMB-WP No. 568.

7. Guleria, Y., \& Verma, O. P. (2018). Impact of financial inclusion through pradhan mantri jan dhan yojana in transforming rural economy, IOSR Journal of Business and Management (IOSR-JBM), 20(12):18-26.

8. Nimbrayan, P. K., Tanwar, N., \& Tripathi, R. K. (2018). Pradhan Mantri Jan DhanYojana (PMJDY): The biggest financial inclusion initiative in the world, Economic Affairs, 63(2), 583-590.

9. Guntupalli, P. S. (2016). Exploring the impacts of Pradhan Mantri Jan-Dhanyojana'- PMJDY, in urban areas, w.r.t. Mumbai, IOSR Journal of Economics and Finance (IOSR-JEF), 82-86.

10. Patnaik, B. C., Satpathy, I., \& Supkar, A. C. (2015). Pradhan Mantri Jan DhanYojna (PMJDY) - a new direction for mainstreaming the financially excluded, National Journal of Management (IJM), 31-42.

11. Paramasivan, R. K. (2015). Public sector banks performance and contribution on Pradhan Mantri Jan Dhan Yojana, International Journal in Commerce, IT \& Social Sciences, 16-23.

12. Aswathy, V. K., \& Shiny, V. N. (2015). PMJDY: A bold path way for financial inclusion, International Journal of Business and Administration Research Review, 126-132.

13. Das, A. N. (2015). Financial inclusion through two selective innovative inter-linkage mechanisms, Intercontinental Journal of Banking, Insurance and Finance, 20-26.

14. Paramasivan. C., \& Kamaraj, R. (2015). Commercial bank's performance on Pradhan Mantri Jan DhanYojana, International Journal of Scientific Research and Education, 3(6):3395-3603. 